\title{
Depression among end-stage renal disease patients undergoing hemodialysis: a cross- sectional study from Palestine
}

Samah W. Al-Jabi i* Ansam Sous², Fatimah Jorf ${ }^{2}$, Mahmoud Taqatqa ${ }^{2}$, Mahdi Allan², Lamees Sawalha², Enas Lubadeh', Waleed M. Sweileh ${ }^{3}$ and Sa'ed H. Zyoud ${ }^{1,4}$

\begin{abstract}
Background: The impact of end-stage renal disease on the patient's psychological status necessitates the value of increasing depression awareness. The current study aimed to assess the depression prevalence among Palestinian hemodialyzed patients and its association with patients' characteristics.

Methods: A convenience clustered sampling technique was followed. Sample was collected from ten hemodialysis centers in the West Bank, Palestine, during 3 months in 2015. We used the Beck Depression Inventory-II scale (BDI-II) to evaluate depression among participants. All data were analyzed using Statistical Package for the Social Sciences version 16.0.

Results: Two hundred and eighty-six hemodialyzed patients were interviewed. The mean age ( \pm standard deviation) of the patients was $52.0 \pm 14.3$ years, and most participants were males 172 (60.1\%). Regarding the dialysis characteristics, the median of years of dialysis was 2 years (1-4). The prevalence of depression was $73.1 \%$. Elderly patients $(p=0.001)$, female $(p=0.036)$, living in rural areas or camp $(p=0.032)$, low income $(p=0.041)$, unemployment $(p=0.001)$, not doing regular exercise $(p=0.001)$, and having multi comorbidities $(p=0.001)$ were significantly associated with more depression scores. The results of binary logistic regression showed that only patients who were living in camps, patients who were previously employed, and patients who were not practicing exercise remained significantly associated with a higher depression score.

Conclusions: This study is the first one confirmed about depression and its prevalence among hemodialyzed patients in the West Bank, Palestine. Compared to other communities, the study found a higher depression prevalence rate. There is a need to offer psychological interviews and non-pharmacological and pharmacological interventions.
\end{abstract}

Keywords: Beck Depression Inventory-II scale, Depression, End-stage renal disease, Hemodialysis, Palestine

\footnotetext{
*Correspondence: samahjabi@najah.edu; samahjabi@yahoo.com

'Division of Clinical and Community Pharmacy, Department of Pharmacy,

Faculty of Medicine and Health Sciences, An-Najah National University,

Nablus, Palestine

Full list of author information is available at the end of the article
}

(c) The Author(s). 2021 Open Access This article is licensed under a Creative Commons Attribution 4.0 International License, which permits use, sharing, adaptation, distribution and reproduction in any medium or format, as long as you give appropriate credit to the original author(s) and the source, provide a link to the Creative Commons licence, and indicate if changes were made. The images or other third party material in this article are included in the article's Creative Commons licence, unless indicated otherwise in a credit line to the material. If material is not included in the article's Creative Commons licence and your intended use is not permitted by statutory regulation or exceeds the permitted use, you will need to obtain permission directly from the copyright holder. To view a copy of this licence, visit http://creativecommons.org/licenses/by/4.0/ The Creative Commons Public Domain Dedication waiver (http://creativecommons.org/publicdomain/zero/1.0/) applies to the data made available in this article, unless otherwise stated in a credit line to the data. 


\section{Background}

The incidence of chronic kidney disease (CKD) worldwide has been increasing annually by $8 \%$, with a total number of more than 1.4 million patients being on renal replacement therapy (RRT) [1]. According to the 2015 Palestinian Ministry of Health Annual Report (MOH), the number of hemodialyzed patients in the West Bank was 1014, who are undergoing dialysis by 175 machines distributed over 11 units [2]. At the time of the study, there were 175 machines in West Bank found in 11 kidney dialysis units in the Ministry of Health hospitals and one unit in An-Najah National University hospital. And there were 139,736 hemodialysis (HD) sessions in total [2].

With the dramatic increase in the incidence of HD, the impact of psychosocial factors on end-stage renal disease (ESRD) patients' outcomes has been lately receiving more consideration. Depression has been recognized to be the most common psychological problem in ESRD patients, which may affect treatment outcomes. According to the World Health Organization report in 2015, 350 million people were depressed [3]. Additionally, the depression prevalence among patients undergoing HD is ranging from 20 to $90 \%$ [4].

To the best of the authors' knowledge, in Palestine, no previous study has been conducted to assess depression status among patients undergoing HD. In addition, few studies were published in Palestine that assessed depression among patients with other diseases [5]. Moreover, some studies have focused on other issues among HD patients [6-10]. Sweileh et al. [5] found that the prevalence of depression among diabetic patients was higher than that observed in other countries, with $40.2 \%$ of patients scored $\geq 16$ according to the Beck Depression Inventory-II (BDI-II) scale. A previous study conducted in Nazareth by Armaly et al. [11] concluded that $43.7 \%$ of HD patients were depressed, and there was a significant difference between cortisol level and depression among the selected subjects.

In Saudi Arabia, AlDukhayel [12] and Turkistani et al. [13] concluded that depression was significantly found in patients with HD. Furthermore, in a previous study, Saeed et al. [14] found that married and unemployed patients on HD were twice more depressed than their caregivers. Moreover, 30\% of Jordanian patients on HD had depression [15].

Furthermore, higher levels of depressive symptoms were observed among HD female patients compared to males [16]. And a previous study found that unemployed and widowed patients who underwent HD had experienced severe depression [17]. In addition, according to BDI-II, $80 \%$ of Iraqi patients on HD had been experiencing depression, with mean score of 17.1. In addition, this study found that Iraqi married unemployed females were significantly more depressed [18].
An Indian study found that the most common psychiatric problem among ESRD patients was depression. Moreover, patients with depression had low quality of life score. Also, those patients needed high burden of care by their clinical staff [19]. Furthermore, an Australian concluded that depression was an independent factor of mortality and morbidity in CKD prior to RRT either in the form of dialysis or transplantation [20].

The current study aimed to assess the prevalence of depression among Palestinian hemodialyzed patients and to assess its association with patients' sociodemographic and clinical characteristics. Depression is widely considered to be the most common psychological problem that can influence the clinical outcomes in patients with ESRD.

Furthermore, identification of depressed ESRD patients and improving the health system in these patients should be considered to improve their outcomes. It is hoped that this study would increase the knowledge about the disease and its benefits, aiding both the medical staff and the patients to improve patients' quality of life. Moreover, this study may help in decreasing therapeutic failure, the need for hospitalization, and even death.

\section{Methods}

\section{Study design and settings}

This study was conducted through a convenience clustered sampling technique to address the research goals. The sample was recruited from dialysis centers at Palestinian Governmental Hospitals (Al-Husein Hospital, Beit-Jala; Khalil Suliman Hospital, Jenin; Thabit Thabit Hospital, Tulkarm; Alia Hospital, Hebron; Abu Al hasan Al kasem Hospital, Yatta; Darwish Nazal Hospital, Qalqilya; An-Najah National University Hospital, Nablus; Jericho Hospital, Jericho; Yasser Arafat Hospital, Salfit; and Palestine Medical Complex, Ramallah). The Ministry of Health provides the main health services in Palestine. Socio-demographic and some clinical-related data were obtained by patients' interview and from the review of their medical records. The data were collected during 4 months, from June 2015 to September 2015.

\section{Sample size}

The number of patients who undergo dialysis by data provided in 2013 was 800 patients [21]. Raosoft sample size calculator (http://www.raosoft.com/samplesize.html) was used to determine the size of the sample needed. In the calculator, the 800-patient figure was used. In addition, the response distribution was set to be $50 \%$, and a margin of error $5 \%$ was allowed at $95 \%$ confidence interval. From these figures, 260 patients were the minimum sample size needed. To enhance reliability and reduce the erroneous results, the target sample size 
was increased, and 286 patients were included. Patients who were 18 years and above, diagnosed and treated at dialysis centers, agreed to participate, and can communicate well with the researcher were included. However, patients who were using medications for depression and/or psychosis, and those with cognitive impairment or exhausted were excluded. Furthermore, a pilot study of 15 patients was used to modify the data collection form before starting the real and final sample that was used in the analysis. The internal consistency for the part of the BDI-II instrument was assessed using Cronbach's $\alpha$ test. The internal consistency of the BDI-II instrument was measured to be 0.857 which shows a good reliability of the BDI-II instrument.

\section{Data collection}

Face-to-face interview was used to collect the data. The structured data collection form that was used to obtain the intended sets of variables consisted of open-ended and close-ended questions. It consisted of many parts:

1) Patient demographic characteristics which include questions about age, gender, body mass index (BMI), level of education, monthly income, locality, employment status, marital status, and family history of renal failure.

2) Clinical questions about history and related disease comorbidities which include number of dialysis per week, years of suffering from renal failure, years of undergoing HD, the interval of dialysis session, smoking status, exercise, using herbal remedies, and comorbidities present (such as hypertension, diabetes mellitus, ischemic heart diseases).

3) Medication and management.

4) Beck Depression Inventory (BDI-II) scale which is used to identify depressive symptoms and the depression intensity, manifested through the person's behavior.

The scale consists of 21 dimensions: sadness, pessimism, past failure, loss of pleasure, guilty feelings, punishment feelings, self-dislike, self-criticalness, suicidal thoughts, crying, agitation, loss of interest, indecisiveness, worthlessness, loss of energy, changes in sleeping patterns, irritability, changes in appetite, concentration difficulty, tiredness, loss of interest in sex. In addition, BDI-II scale assesses symptom intensity, and each item is classified from 0 to 3 (i.e., absent to severe symptoms; almost unbearable). The score was calculated through summation of the responses for the 21 items, and the score of the degree of depression was classified as follows: 0 to 13 (minimal depression), 14 to 19 (mild depression), 20 to 28 (moderate depression), and 29 to 63 (severe depression) [22-24]. The BDI-II scale was translated into Arabic and validated to be used to assess depression. Additionally, permission to use this edition was obtained from the author [25, 26]. In addition, the cutoff point score used for depression was 16 and higher, which was used in some previous studies [5, 27], one of which was previously published in Palestine [5]. Furthermore, Lustman et al. [27] concluded that the best balance between positive predictive value and sensitivity was shown by a cutoff score of $>$ or $=16$ for the entire 21item scale. In addition, internal consistency was ensured using Cronbach's alpha; the Cronbach's alpha value was $86 \%$ for the BDI-II scale used in the study.

\section{Ethical approval}

Before the beginning of this study, the protocol was approved by the An-Najah National University Institutional Review Board (IRB) with an archived approval number of 38/April/2015, in addition to the local health authorities. Furthermore, the purposes and procedures of the study were explained by the interviewer before commencing the interview, and a verbal consent was obtained.

\section{Statistical analysis}

The data gathered were quantitatively analyzed by utilizing Statistical Package for the Social Sciences (SPSS version 16). The categorical variables were illustrated as frequencies with their percentages. KolmogorovSmirnov test was used to test the normality of continuous variables; those variables that were distributed normally were expressed as mean \pm standard deviation (SD). However, continuous variables that were not normally distributed were expressed as the median with their interquartile range. Further statistical analysis was used to determine the association between demographic characteristics, clinical characteristics, patients' comorbid diseases, and patients' medications with depression. The Chi-square was used to test the significance between the categorical variables. In addition, Student's $t$ test or Mann-Whitney $U$ test, whichever is appropriate, was used to compare the means of continuous variables. Furthermore, to test the significant correlations between continuous variables, Spearman's correlation was used. A $p$ value $<0.05$ was considered significant. In addition, all of the significant variables in the univariate analysis were included in the binary logistic regression model to control for the possible impact of any candidate confounding factors. Binary logistic regression was used to determine which variables were significantly correlated with higher depression levels.

\section{Results}

Socio-demographic characteristics

In total, 298 patients were interviewed, and 286 approved to participate with a response rate of $95 \%$. Their 
distribution from the $10 \mathrm{HD}$ centers were as follows: 55 (19.2\%) from Alia Hospital, Hebron; 55 (19.2\%) from An-Najah National University Hospital, Nablus; 40 (13.9\%) from Palestine Medical Complex Hospital, Rammalah; 38 (13.3\%) from Khalil Suliman Hospital, Jenin; 28 (9.8\%) from Al-Husein Hospital, Beit Jala; 25 (8.8\%) from Thabit Thabit Hospital, Tulkarm; 16 (5.6\%) from Darwish Nazal Hospital, Qalqilya; 12 (4.2\%) from Abu Alhasan Al kasem Hospital, Yatta; 9 (3.2\%) from Jericho Hospital, Jericho; and 8 (2.8\%) from Yasser Arafat Hospital, Salfit.

Table 1 shows the patients' socio-demographic characteristics. The patients' mean age $( \pm$ SD) was $52.8 \pm 14.3$ years, with a range from 19 to 84 years. Among the 286 patients included, 172 (60.1\%) were male. According to the patient's BMI, most of the patients $(118,41.3 \%)$ have normal weight. Furthermore, the majority of those patients interviewed (200, 69.9\%) were married. Regarding the level of education, 132 (46.2\%) patients completed primary education. Furthermore, most of the patients were living in village 185 (64.7\%) followed by 85 (29.7\%) living in urban areas. Regarding the monthly income of the patients, most of the patients $(167,58.4 \%)$ have monthly income less than 2000 NIS. Regarding their employment status, 133 (46.5\%) previously worked, and only $42(14.7 \%)$ were still working.

Moreover, out of 286 patients, 73 (25.5\%) have a family history of renal disease. In addition, regarding their smoking habits, 59 (20.6\%) are smokers with a median smoking year of 20 (9-29). When the patients were asked about exercise, the majority 219 (76.6\%) did not do exercise.

\section{History of renal disease}

The median (interquartile range) of the years that the patients had been suffering from renal failure and the years in which those patients underwent HD was 4.0 (2.0-8.0) and 2.0 (1.0-4.0), respectively. In addition, the median number of dialysis per week was 3.0 (3.0-3.0) and the median of hours of dialysis session was 3.5 (3.0-3.5).

\section{Comorbid diseases among the study patients}

The majority of patients suffered from hypertension 233 (81.5\%), followed by diabetes mellitus 138 (48.3\%) and anemia 131 (45.8\%).

\section{Chronic medications used by the study patients}

According to patient's medications, calcium carbonate, 272 (95.1\%); alfacalcidol, 252 (88.1\%); amlodipine, 171 (59.8\%); and furosemide, 152 (53.1\%), were the most commonly used medications.

\section{Depression among the studied patients using Beck (BDI-II) scale}

The reported depression score as measured by the mean $( \pm \mathrm{SD})$ BDI-II score was $23.66 \pm 10.87$. Furthermore, regarding the classification of depression scores, 97 (33.9\%) participants were moderately depressed followed by 83 (29\%) severely depressed. In addition, 55 (19.2\%) patients were minimally and $51(17.8 \%)$ patients were mildly depressed. Furthermore, the majority of participants $209(73.1 \%)$ had their depression score more than 16 , while $77(26.9 \%)$ patients scored less or equal to 16 in the depression scale.

\section{Factors associated with depression}

As shown in Table 2, patients who were 60 years old and more were more depressed (40.2\% versus $22.1 \%, p=$ 0.001). Moreover, significantly, gender was associated with depression; female patients were more depressed (43.5\% versus $29.9 \%, p=0.036$ ). Regarding income status, there was a significant association between income and depression $(p=0.041)$. Patients with low income have a higher depression score compared to patients with moderate to high income (62.7\% versus $46.8 \%)$.

In addition, there was a significant association between locality and depression $(p=0.032)$. Patients who were living in rural areas (66.5\% versus $59.7 \%)$ and in camps (7.2\% versus $1.3 \%$ ) were more depressed than those living in urban areas.

Regarding employment status, participants who are previously employed before renal failure (50.7\% versus $35.1 \%)$ and unemployed patients (40.7\% versus $33.8 \%)$ were significantly more depressed $(p=0.001)$. In addition, 179 (85.6\%) of the patients who did not make any exercise had experienced a higher depression score (85.6\% versus $51.9 \%, p=0.001$ ).

Furthermore, there was a significant association between the number of medications used and depression score; patients with higher median number of medications were having higher depression scores $(p=0.039)$. In addition, regarding the comorbid diseases, there was a significant association between depression score and higher number of disease comorbidities. Patients with three or more chronic comorbid diseases were significantly more depressed $(72.7 \%$ versus $35.1 \%, p=0.001)$, (Table 3).

However, there was no significant difference between years of dialysis and depression $(p=0.223)$, number of dialysis per week and depression $(p=0.680)$, and between duration of dialysis session and depression ( $p=$ 0.414). In addition, no significant difference was found between patients who had hemodialysis sessions of less than $3.5 \mathrm{~h}$ or who had hemodialysis session of $3.5 \mathrm{~h}$ and more and the depression score level $(p=0.273)$. 
Table 1 Sociodemographic characteristics of the study patients

\begin{tabular}{ll}
\hline Variables & Mean ( \pm SD ), frequency (\%), \\
median (interquartile range) \\
$(N=286)$
\end{tabular}

\begin{tabular}{ll}
\hline $\begin{array}{l}\text { Gender } \\
\text { Male }\end{array}$ & $172(60.1)$ \\
Female & $114(39.9)$ \\
Age & $52.8 \pm 14.3$ \\
Age category & \\
$<30$ & $28(9.8)$ \\
$30-60$ & $157(54.9)$ \\
$>60$ & $101(35.3)$
\end{tabular}

\section{BMI category}

Normal $(<25)$

$118(41.3)$

Overweight (25-30)

Obese (> 30)

$96(33.6)$

$72(25.2)$

\section{Education}

No formal education

$29(10.1)$

Primary

Secondary

$132(46.2)$

$86(30.1)$

University

$22(7.7)$

Post-graduate

$17(5.9)$

Income

High (more than 5000 NIS )

9 (3.1)

Moderate (2000-5000 NIS )

$110(38.5)$

Low (less than 2000 NIS)

$167(58.4)$

\section{Marital status}

Married

$200(69.9)$

Single

45 (15.7)

Divorced

$7(2.4)$

Widowed

$34(11.9)$

\section{Locality of patient}

Urban

85 (29.7)

Rural

$185(64.7)$

Camp

$16(5.6)$

\section{Worship}

$\begin{array}{ll}\text { Not practice } & 7(24) \\ \text { Seldom practice } & 29(10.1) \\ \text { Regular practice } & 250(87.4)\end{array}$

\section{Employment status}

Unemployed

$111(38.8)$

Employed

$42(14.7)$

Previously employed

Family history
Table 1 Sociodemographic characteristics of the study patients (Continued)

\begin{tabular}{ll}
\hline Variables & $\begin{array}{l}\text { Mean ( } \pm \text { SD ), frequency (\%), } \\
\text { median (interquartile range) } \\
(\mathbf{N = 2 8 6 )}\end{array}$ \\
\hline Smoking & $59(20.6)$ \\
Current smoking & $67(23.4)$ \\
Previously smoked & $160(55.9)$ \\
Nonsmoker & $20(9-29)$ \\
Years of smoking & \\
Exercise & $67(23.4)$ \\
Yes & $219(76.6)$ \\
No & \\
Times of exercise & $219(75.9)$ \\
None & $10(3.5)$ \\
Once weekly & $14(4.9)$ \\
Twice weekly & $10(3.5)$ \\
Three times weekly & $4(1.4)$ \\
Four times weekly & $1(0.3)$ \\
Five times weekly & $4(1.4)$ \\
Six times weekly & $24(8.4)$ \\
Seven times weekly &
\end{tabular}

The binary logistic regression model results are clarified in Table 4. We used the BDI-II depression score cutoff of 16 as a dependent variable, and age, gender, income, locality, employment status, practicing exercise, number of chronic diseases, and number of medications as independent variables. The results showed that only patients who were living in camps (odds ratio $(\mathrm{OR})=9.91$; 95\% confidence interval $(\mathrm{CI})=1.10-89.19 ; p=0.041)$, patients who were previously employed ( $\mathrm{OR}=3.95$; $95 \%$ $\mathrm{CI}=1.61-9.67 ; p=0.003)$, and patients who were not practicing exercise $(\mathrm{OR}=4.43 ; 95 \% \mathrm{CI}=2.19-8.96 ; p<$ 0.001) remained significantly associated with higher depression score (Table 4).

\section{Discussion}

Depression is a psychiatric condition that affects the diagnosis of a variety of medical conditions, including ESRD [11]. However, compared to the general population, patients on HD have higher incidence of depression. Moreover, depression is underdiagnosed in HD patients because of dealing with patients with depressed mood and because of the nature of their illness [13].

To the best of the authors' knowledge, this study is the first one in the West Bank, Palestine, that assesses depression and its associated factors among ESRD patients.

Past studies have reported that depression in HD patients ranges from 25.3 to $60.5 \%$ using different scales and populations [13]. In Palestine, there is a lack of data 
Table 2 Factors associated with depression

\begin{tabular}{|c|c|c|c|c|}
\hline \multirow[t]{2}{*}{ Variable } & \multirow[t]{2}{*}{ Total } & \multicolumn{2}{|c|}{ BDI-II depression score } & \multirow[t]{2}{*}{$p$ value } \\
\hline & & $\leq 16$ & $>16$ & \\
\hline Age category & & & & $0.001^{a}$ \\
\hline Less than 30 & $28(9.8 \%)$ & $14(18.2 \%)$ & $14(6.7 \%)$ & \\
\hline $30-60$ & $157(54.9 \%)$ & $46(59.7 \%)$ & $111(53.1 \%)$ & \\
\hline More than 60 & $101(35.3 \%)$ & $17(22.1 \%)$ & $84(40.2 \%)$ & \\
\hline Gender & & & & $0.036^{\mathrm{a}}$ \\
\hline Male & $172(60.1 \%)$ & $54(70.1 \%)$ & $118(56.5 \%)$ & \\
\hline Female & $114(39.9 \%)$ & $23(29.9 \%)$ & 91 (43.5\%) & \\
\hline BMI category & & & & $0.147^{a}$ \\
\hline Normal (less than 25) & $118(41.3 \%)$ & $35(45.5 \%)$ & $83(39.7 \%)$ & \\
\hline Overweight (25-30) & $96(33.6 \%)$ & $29(37.7 \%)$ & $67(32.1 \%)$ & \\
\hline Obese (over than 30) & $72(25.2 \%)$ & $13(16.9 \%)$ & $59(28.2 \%)$ & \\
\hline Level of education & & & & $0.073^{b}$ \\
\hline No formal education & $29(10.1 \%)$ & $4(5.2 \%)$ & $25(12 \%)$ & \\
\hline Primary & $132(46.2 \%)$ & $29(37.7 \%)$ & $103(49.3 \%)$ & \\
\hline Secondary & $86(30.1 \%)$ & $30(39 \%)$ & $56(26.8 \%)$ & \\
\hline University & $22(7.7 \%)$ & $8(10.4 \%)$ & $14(6.7 \%)$ & \\
\hline Postgraduate & 17 (5.9\%) & $6(7.8 \%)$ & $11(5.3 \%)$ & \\
\hline Income & & & & $0.041^{b}$ \\
\hline Low (less than 2000NIS) & $167(58.4 \%)$ & $36(46.8 \%)$ & $131(62.7 \%)$ & \\
\hline Moderate (2000-5000NIS) & $110(38.5 \%)$ & $37(48.1 \%)$ & $73(34.9 \%)$ & \\
\hline High (more than 5000NIS) & $9(3.1 \%)$ & $4(5.2 \%)$ & $5(2.4 \%)$ & \\
\hline Marital status & & & & $0.119^{b}$ \\
\hline Married & $200(69.6 \%)$ & $54(70.1 \%)$ & $146(69.9 \%)$ & \\
\hline Single & $45(15.7 \%)$ & $17(22.1 \%)$ & $28(13.4 \%)$ & \\
\hline Divorced & $7(2.4 \%)$ & $1(1.3 \%)$ & $6(2.9 \%)$ & \\
\hline Widowed & $34(11.9 \%)$ & $5(6.5 \%)$ & $29(13.9 \%)$ & \\
\hline Locality of patients & & & & $0.032^{\mathrm{b}}$ \\
\hline Urban & $85(29.7 \%)$ & 30 (39.0\%) & $55(26.3 \%)$ & \\
\hline Rural & $185(64.7 \%)$ & $46(59.7 \%)$ & $139(66.5 \%)$ & \\
\hline Camp & $16(5.6 \%)$ & $1(1.3 \%)$ & $15(7.2 \%)$ & \\
\hline Employment status & & & & $0.001^{\mathrm{a}}$ \\
\hline Unemployed & $111(38.8 \%)$ & $26(33.8 \%)$ & $85(40.7 \%)$ & \\
\hline Employed & $42(14.7 \%)$ & $24(31.2 \%)$ & $18(8.6 \%)$ & \\
\hline Previously employed before renal failure & $133(46.5 \%)$ & $27(35.1 \%)$ & $106(50.7 \%)$ & \\
\hline Family history of renal failure & & & & $0.084^{\mathrm{a}}$ \\
\hline Yes & $73(74.5 \%)$ & $14(18.2 \%)$ & $59(28.8 \%)$ & \\
\hline No & $213(25.5 \%)$ & $63(81.8 \%)$ & $150(71.8 \%)$ & \\
\hline Herbal use & & & & $0.261^{\mathrm{a}}$ \\
\hline Yes & $159(44.4 \%)$ & 47 (61.0\%) & $112(53.6 \%)$ & \\
\hline No & $127(55.6 \%)$ & 30 (39.0\%) & 97 (46.4\%) & \\
\hline Smoking & & & & $0.721^{a}$ \\
\hline Current smoker & 59 (20.6\%) & 15 (19.5\%) & 44 (21.1\%) & \\
\hline Previously smoked & 67 (23.4\%) & $16(20.8 \%)$ & $51(24.4 \%)$ & \\
\hline
\end{tabular}


Table 2 Factors associated with depression (Continued)

\begin{tabular}{|c|c|c|c|c|}
\hline \multirow[t]{2}{*}{ Variable } & \multirow[t]{2}{*}{ Total } & \multicolumn{2}{|c|}{ BDI-II depression score } & \multirow[t]{2}{*}{$p$ value } \\
\hline & & $\leq 16$ & $>16$ & \\
\hline Non-smoker & $160(55.9 \%)$ & $46(59.7 \%)$ & $114(54.5 \%)$ & \\
\hline Exercise & & & & $0.001^{\mathrm{a}}$ \\
\hline Yes & $67(23.4 \%)$ & $37(48.1 \%)$ & $30(14.4 \%)$ & \\
\hline No & $219(76.6 \%)$ & $40(51.9 \%)$ & $179(85.6 \%)$ & \\
\hline Number of medications & $7(6-9)$ & $7(6-9)$ & $8(6-9)$ & $0.039^{c}$ \\
\hline
\end{tabular}

BDI-II Beck Depression Inventory-II scale, BMI body mass index, NIS New Israeli Shekel (1 NIS = 0.31 US dollars)

${ }^{\text {a }}$ Statistical significance of differences calculated using the chi-square test

${ }^{\mathrm{b}}$ Statistical significance of differences calculated using Fisher's exact test

'Statistical significance of differences calculated using Mann-Whitney $U$ test

about depression; one study showed that depression occurs in $40.2 \%$ of diabetic patients [5]. In addition, $15 \%$ of Palestinian women randomly selected from Gaza Strip areas had moderate to severe depression [28]. Moreover, the lifetime and 1-month prevalence of major depression episodes in a multi-stage sample of 916 adult Palestinians was found to be $24.3 \%$ and $10.6 \%$, respectively [29]. Our study shows a higher incidence of depression among ESRD patients, and the results indicated that the prevalence of depression (i.e., score more than 16) in our patients is $73.1 \%$. Furthermore, in a previous study, Zyoud et al. [10] reported that health-related quality of life of Palestinian hemodialyzed patients according to EuroQOL-5 Dimension instrument was found to be $0.37 \pm 0.44$, and their Euro QOL visual analog scale score was $59.38 \pm 45.39$. This may be related to multiple factors, such as disease-related factors, patient-related factors, community-related ones, stressful life, and the lack of entrainment activities. This result is consistent with a study in Pakistan that showed that depression occurs in $72 \%$ of patients on HD [18].

The participants of our study were moderately to severely depress with an incidence of more than $60 \%$. This result is consistent with a previous study conducted by Nabolsi et al. [16]. Our explanation may be due to high incidence of chronic comorbidities, long dialysis sessions, far distance between locality of the patients and dialysis centers, and the absence of social and psychiatric support.

Furthermore, the current study found a significant relationship between age and depression, which is consistent with that observed in other studies. However, this study shows that patients 60 years old and more were more depressed; this may be related to physiological changes and prevalence of comorbidities. This result agreed with the result done by Turkistani et al. [13] which showed that older patients were significantly depressed. However, another study found that the prevalence of depression was found to be higher among younger patients (20 to 40 years) [18]. On the other hand, previous studies showed that there was no significant association between depression and patients' age [30, 31].

Regarding depression and gender association, a previous study found that there was no relation between gender and depression [30] while others found that females had more depression than males [5, 11, 16, 17, 32], which is consistent with the results found in our study. This may explain that females have more stressors in that they have to play major social roles, such as being a wife, a mother, or a sister.

Furthermore, the current study showed that there is no significant relationship between higher depression scores and patients' marital status $(p=0.119)$. However, Armaly et al. [11] reported that unmarried patients were two-fold depressed more than married ones. In contrast to that result, a study in Saudi Arabia resulted in that married patients were more depressed than single [12]. Furthermore, another study has reported that divorced participants were less likely to have depressive disorder compared to those who are married [33].

Table 3 Association between depression and number of comorbidities

\begin{tabular}{llll}
\hline Variable & Total & \multicolumn{1}{l}{ BDI-II depression score } & $>16$ \\
\cline { 3 - 4 } & & $\leq \mathbf{1 6}$ & $2(1.0 \%)$ \\
\hline None of chronic comorbid disease & $5(1.7 \%)$ & $3(3.9 \%)$ & $17(8.1 \%)$ \\
One chronic comorbid disease & $40(14.0 \%)$ & $23(29.9 \%)$ & $38(18.2 \%)$ \\
Two chronic comorbid diseases & $62(21.7 \%)$ & $24(31.2 \%)$ & $152(72.7 \%)$ \\
Three or more chronic comorbid diseases & $179(62.6 \%)$ & $27(35.1 \%)$ & a \\
\hline
\end{tabular}

BDI-II Beck Depression Inventory-II scale

${ }^{\text {a }}$ Statistical significance of differences calculated using Fisher's exact test 
Table 4 Independent factors associated with depression using binary logistic regression analysis

\begin{tabular}{|c|c|c|c|c|c|}
\hline Variable & $B$ & S.E. & Wald & Sig. & Odds ratio (95\% C.I.) \\
\hline \multicolumn{6}{|l|}{ Age category } \\
\hline Less than 30 & & & & Ref. & \\
\hline $30-60$ & -0.53 & 0.55 & 0.93 & 0.334 & $0.59(0.20-1.73)$ \\
\hline More than 60 & 0.07 & 0.62 & 0.01 & 0.914 & $1.07(0.32-3.59)$ \\
\hline \multicolumn{6}{|l|}{ Gender } \\
\hline Male & & & & Ref. & \\
\hline Female & 0.54 & 0.45 & 1.45 & 0.228 & $1.72(0.71-4.13)$ \\
\hline \multicolumn{6}{|l|}{ Income } \\
\hline High (more than 5000 NIS) & & & & Ref. & \\
\hline Moderate (2000-5000 NIS) & 0.76 & 0.89 & 0.71 & 0.398 & $2.13(0.37-12.29)$ \\
\hline Low (less than 2000 NIS) & 0.17 & 0.89 & 0.04 & 0.845 & $1.19(0.21-6.86)$ \\
\hline \multicolumn{6}{|l|}{ Locality of patients } \\
\hline Urban & & & & Ref. & \\
\hline Rural & 0.67 & 0.35 & 3.63 & 0.057 & $1.94(0.98-3.85)$ \\
\hline Camp & 2.29 & 1.12 & 4.19 & 0.041 & $9.91(1.10-89.19)$ \\
\hline \multicolumn{6}{|l|}{ Employment status } \\
\hline Employed & & & & Ref. & \\
\hline Unemployed & 0.66 & 0.56 & 1.37 & 0.242 & $1.93(0.64-5.83)$ \\
\hline Previously employed & 1.37 & 0.46 & 9.03 & 0.003 & $3.95(1.61-9.67)$ \\
\hline \multicolumn{6}{|l|}{ Exercise } \\
\hline Yes & & & & Ref. & \\
\hline No & 1.49 & 0.36 & 17.13 & 0.000 & $4.43(2.19-8.96)$ \\
\hline \multicolumn{6}{|l|}{ Chronic comorbid disease } \\
\hline None & & & & Ref. & \\
\hline One & -0.60 & 1.19 & 0.25 & 0.616 & $0.55(0.05-5.67)$ \\
\hline Two & 0.01 & 1.21 & 0.00 & 0.990 & $1.02(0.10-10.82)$ \\
\hline Three or more & 1.25 & 1.22 & 1.04 & 0.309 & $3.47(0.32-38.17)$ \\
\hline Number of medications & -0.04 & 0.08 & 0.26 & 0.610 & $0.96(0.82-1.13)$ \\
\hline
\end{tabular}

$B$ coefficient of predictor variables, CI confidence interval, NIS New Israeli Shekel (1 NIS = 0.31 US dollars), S.E standard error

Some researchers concluded that patients who were not working or had low income had a higher level of depression $[5,11,12,14]$. Nearly more than half of the study population had a low monthly income, which was associated with increased depression scores. In addition, when the employment status was analyzed, we found out that employed patients were significantly less depressed than previously employed or not employed patients. Although, the causes of why they left their jobs were not assessed, the significantly higher scores of depression among patients who were not working may be due to the following reasons. Previous studies have reported that prolonged unemployment was associated with increased stress in individuals [33, 34]. Moreover, nearly $40 \%$ of patients who were not working were more than 60 years old, and this age is the age that most institutions rely on for retirement. In addition, a previous study has found that a higher proportion of HD patients reflects increased fatigue and debility that renders them incapable of working effectively [14]. In addition, concerning the patients who were not working, the median number of dialysis per week was 3.0 with the median hours of dialysis session of $3.5 \mathrm{~h}$; this may make them unable to contribute to their work and may make some restrictions for them to work such as limitation of workload and decline of working hours [35].

The study also shows that there is no relation between depression and either BMI or educational level. However, a previous study found that patients with abnormal high BMI had more depression [5]. Additionally, some studies found that patients with a low level of education were more depressed $[5,11,12]$.

The results of the current study indicate higher depression scores among patients who were living in rural 
areas and in camps more than those living in urban areas. Usually, people living in villages or camps have less income than people living in urban areas. In addition, when the income status was examined for rural and camp patients, we found out that almost $60 \%$ of rural and camp patients had a low monthly income. Furthermore, this difference may be attributed not only due to low income but also to other factors, such as the far distance between their living places, transportation difficulties, and absence of appropriate health services near to their living.

According to exercise practicing, this study shows a significant association between exercising regularly and depression. Patients who did not make any exercise had higher depression levels than those who exercise regularly. The mechanism for exercise-depression relationship is still unclear. The most logical hypothesis is that exercise increases the availability of neurotransmitters (serotonin, norepinephrine, and dopamine) which oppose depression, known as monoamine hypothesis. Furthermore, psychological exercise amuses from solitude and depression [36]. In addition, it can be difficult for patients with depression to start and maintain an exercise regimen. Depressive symptoms such as tiredness, indecisiveness, low self-esteem, loss of interest and pleasure, and poor sleep can affect motivation for exercise [37]. Higher anxiety levels in those patients may be at particular risk for noncompliance with exercise [38]. However, as this study was cross-sectional, this may prevent cause-effect relationship between exercise and depression to be identified.

Regarding disease comorbidities and medications used, there is a strong association between disease comorbidities and depression. The majority of our patients with three or more chronic comorbid diseases are significantly more depressed compared with patients with one, two, or without any comorbidities. Furthermore, this study shows a significant correlation between depression score and number of medications; patients who took multi-medications were more depressed than others.

Regarding dialysis-related parameters, there was no significant association between years of dialysis, number of dialysis per week, and duration of dialysis session and depression. In the current study, the median number of dialysis per week was 3.0, and the median of hours of dialysis session was $3.5 \mathrm{~h}$. Although the standard duration of hemodialysis sessions is more than $3.5 \mathrm{~h}$ per session (4.5-5.0 h) [39], no significant difference was found between patients who had hemodialysis sessions of less than $3.5 \mathrm{~h}$ or who had hemodialysis sessions of $3.5 \mathrm{~h}$ and more and the depression score level.

The current study is the first of its kind in West Bank, Palestine, regarding depression and its associated factors among HD patients. The study included the appropriate sample size from all HD centers in West Bank, Palestine. The data were gathered via face-to-face interview, which can result in entire and valid data, can capture verbal and non-verbal ques and emotions, and can make the patient focus while giving their answers. Moreover, the findings of this study will be the base for future studies about depression and other outcomes in HD patients in Palestine.

Furthermore, identification of depressed ESRD patients and improving the health system in these patients should be considered in different ways. These include establishing a program with psychiatric specialists and social support volunteers for the diagnosis and management of depression. In addition, different indicators are to be used to improve patients' mental thoughts, increasing awareness and knowledge towards adherence to their treatment regularly via making meetings and brochures and other advises to improve their quality of life and minimizing complications, costs, medication errors, and even death.

However, the current study had some limitations; faceto-face interviews may introduce a bias in patients who may want to respond in a private way, thus may generate socially desirable answers. Furthermore, the study was cross-sectional in its nature, which may prevent causeeffect relationships to be identified. In addition, the absence of control groups (i.e., hemodialysis depressed patients versus non-hemodialysis depressed patients) limits the interpretation of the hemodialysis burden on depression.

\section{Conclusions}

This study is the first one regarding depression and its prevalence among HD patients in West Bank, Palestine. The incidence of depression is higher than that reported in other communities and has never been measured before. Elderly patient, female, living in rural areas or camp, low income, not doing regular exercise, unemployment, and having multi comorbidities were significantly associated with more depression scores. However, the results of binary logistic regression showed that only patients who were living in camps, patients who were previously employed, and patients who were not practicing exercise remained significantly associated with higher depression score. Our recommendations focused on three axis: hospital staff, patients, and further studies. The governmental hospitals need a multidimensional team of nephrologists, clinical pharmacists, nurses, psychologists, and social workers for early detection of depression. The clinicians must have skills in well-validated screening measurements for improving quality of life, decrease hospitalization and increase survival. Additionally, providing the patient's needs in terms of psychologist interviews and pharmacological and nonpharmacological interventions (family support, patient education, and antidepressant medications) is needed. 


\section{Abbreviations}

BDI-II: Beck Depression Inventory-II scale; BMI: Body mass index; BSA: Body surface area; CKD: Chronic kidney disease; Cl: Confidence interval; ESRD: Endstage renal disease; GFR: Glomerular filtration rate; HD: Hemodialysis; IRB: Institutional Review Board; MOH: Ministry of Health; KDOQI: Kidney Disease Outcomes Quality Initiatives; NIS: New Israeli Shekel; OR: Odds ratio; RRT: Renal replacement therapy; SD: Standard deviation; SPSS: Statistical Package for the Social Sciences

\section{Acknowledgements}

The authors would like to thank the Palestinian Ministry of Health $(\mathrm{MOH})$, the Hospitals' staff and health care providers, and hemodialysis patients for giving opportunities to obtain the needed information.

\section{Authors' contributions}

SA had the idea for the study and led the study design, data analysis and interpretation, and drafting of the manuscript. AS, FJ, MT, MA, LS, and EL interviewed patients and participated in data interpretation and drafting. SZ and WS had the idea for the study, participated in the study design, and revised the article for important intellectual content. All authors read and approved the final manuscript and agreed on its submission.

\section{Funding}

No funding was received for conducting this study.

\section{Availability of data and materials}

The datasets supporting the conclusions of this article are included within the article and available upon request.

\section{Declarations}

Ethics approval and consent to participate

All aspects of the study protocol were authorized by the An-Najah National University Institutional Review Board (IRB) and Palestinian Ministry of Health $(\mathrm{MOH})$ before initiating this study. Patients were included after we obtained their verbal consent.

\section{Consent for publication}

Authors' abstract was accepted in The Lancet Palestinian Health Alliance (LPHA) Eighth Annual Conference, 2017. Thereafter, it was published in the Lancet as abstract (2018;391 Suppl 2:S41. doi: 10.1016/S0140-6736(18)30407-0).

\section{Competing interests}

The authors declare that they have no competing interests.

\section{Author details}

'Division of Clinical and Community Pharmacy, Department of Pharmacy, Faculty of Medicine and Health Sciences, An-Najah National University, Nablus, Palestine. ${ }^{2}$ Department of Pharmacy, Faculty of Medicine and Health Sciences, An-Najah National University, Nablus, Palestine. ${ }^{3}$ Division of Physiology and Pharmacology, Department of Biomedical Sciences, Faculty of Medicine and Health Sciences, An-Najah National University, Nablus, Palestine. ${ }^{4}$ Clinical Research Center, An-Najah National University Hospital, Nablus 44839, Palestine.

Received: 30 June 2020 Accepted: 21 February 2021 Published online: 06 March 2021

\section{References}

1. White SL, Chadban SJ, Jan S, Chapman JR, Cass A. How can we achieve global equity in provision of renal replacement therapy? Bull World Health Organ. 2008:86(3):229-37.

2. Palestinian Ministry Of Health. Health annual report, 2015. 2016. http://site moh.ps/Content/Books/FDVFRuU5ORaxrOaq4C5Q987a3GBwIIDpumLa fURDQJcT7ggdf9Yk13_UEpLZXH64SsaOSyrQeQIET7OljGkpE1QXz4 8MqlmMZXIgFpARQZQdE.pdf (accessed 20 May 2017).

3. World Health Organization. World Health Statistics 2015. 2015. http://apps. who.int/iris/bitstream/10665/170250/1/9789240694439_eng.pdf (accessed 7 Apr 2016.
4. Khalil AA, Frazier SK, Lennie TA, Sawaya BP. Depressive symptoms and dietary adherence in patients with end-stage renal disease. J Ren Care. 2011;37(1):30-9.

5. Sweileh WM, Abu-Hadeed HM, Al-Jabi SW, Zyoud SH. Prevalence of depression among people with type 2 diabetes mellitus: a cross sectional study in Palestine. BMC Public Health. 2014;14:163.

6. Khatib ST, Hemadneh MK, Hasan SA, Khazneh E, Zyoud SH. Quality of life in hemodialysis diabetic patients: a multicenter cross-sectional study from Palestine. BMC Nephrol. 2018;19(1):49.

7. Naalweh KS, Barakat MA, Sweileh MW, Al-Jabi SW, Sweileh WM, Zyoud SH Treatment adherence and perception in patients on maintenance hemodialysis: a cross - sectional study from Palestine. BMC Nephrol. 2017; 18(1):178.

8. Omari AM, Omari LS, Dagash HH, Sweileh WM, Natour N, Zyoud SH. Assessment of nutritional status in the maintenance of haemodialysis patients: a cross-sectional study from Palestine. BMC Nephrol. 2019;20(1):92.

9. Zyoud SH, Al-Jabi SW, Sweileh WM, Tabeeb GH, Ayaseh NA, Sawafta MN, Khdeir RL, Mezyed DO, Daraghmeh DN, Awang R. Use of complementary and alternative medicines in haemodialysis patients: a cross-sectional study from Palestine. BMC Nephrol. 2016;16:204

10. Zyoud SH, Daraghmeh DN, Mezyed DO, Khdeir RL, Sawafta MN, Ayaseh NA, Tabeeb GH, Sweileh WM, Awang R, Al-Jabi SW. Factors affecting quality of life in patients on haemodialysis: a cross-sectional study from Palestine. BMC Nephrol. 2016;17(1):44

11. Armaly Z, Farah J, Jabbour A, Bisharat B, Qader AA, Saba S, Zaher M, Haj EE, Hamzi M, Bowirrat A. Major depressive disorders in chronic hemodialysis patients in Nazareth: identification and assessment. Neuropsychiatr Dis Treat. 2012;8:329-38.

12. AIDukhayel A. Prevalence of depressive symptoms among hemodialysis and peritoneal dialysis patients. Int J Health Sci (Qassim). 2015;9(1):9-16.

13. Turkistani I, Nuqali A, Badawi M, Taibah O, Alserihy O, Morad M, Kalantan E. The prevalence of anxiety and depression among end-stage renal disease patients on hemodialysis in Saudi Arabia. Ren Fail. 2014;36(10):1510-5.

14. Saeed Z, Ahmad AM, Shakoor A, Ghafoor F, Kanwal S. Depression in patients on hemodialysis and their caregivers. Saudi J Kidney Dis Transpl. 2012:23(5):946-52

15. Khalil AA, Frazier SK. Depressive symptoms and dietary nonadherence in patients with end-stage renal disease receiving hemodialysis: a review of quantitative evidence. Issues Ment Health Nurs. 2010;31(5):324-30.

16. Nabolsi MM, Wardam L, Al-Halabi JO. Quality of life, depression, adherence to treatment and illness perception of patients on haemodialysis. International Journal of Nursing Practice. 2015:21(1):1-10.

17. Ibrahim S, El Salamony O. Depression, quality of life and malnutritioninflammation scores in hemodialysis patients. Am J Nephrol. 2008;28(5):784-91.

18. Hamody AR, Kareem AK, Al-Yasri AR, Sh Ali AA. Depression in Iraqi hemodialysis patients. Arab J Nephrol Transplant. 2013;6(3):169-72.

19. Jadhav BS, Dhavale HS, Dere SS, Dadarwala DD. Psychiatric morbidity, quality of life and caregiver burden in patients undergoing hemodialysis. Med J Dr DY Patil University. 2014;7(6):722-7.

20. McKercher C, Sanderson K, Jose MD. Psychosocial factors in people with chronic kidney disease prior to renal replacement therapy. Nephrology (Carlton). 2013;18(9):585-91.

21. Palestinian Ministry Of Health. Annual Health Report. 2013. http://moh.ps/ Content/Books//ZfCegfK8x8iPi2chru2BzRuhBGtZJvLrInpkmvBOrTJW19sbqa LSg_vw5C6cVwrwo6LNUJxICTFxBISUfN1v4SDpqkycKL7zNJf16eUx5TBk.pdf (accessed 8 June 2015

22. Beck AT, Steer RA, Ball R, Ranieri W. Comparison of Beck Depression Inventories -IA and -II in psychiatric outpatients. J Pers Assess. 1996;67(3): 588-97.

23. Beck AT, Guth D, Steer RA, Ball R. Screening for major depression disorders in medical inpatients with the Beck Depression Inventory for primary care. Behav Res Ther. 1997:35(8):785-91.

24. Steer RA, Ball R, Ranieri WF, Beck AT. Further evidence for the construct validity of the Beck depression Inventory-II with psychiatric outpatients. Psychol Rep. 1997;80(2):443-6.

25. Alansari BM. Beck Depression Inventory (BDI-II) items characteristics among undergraduate students of nineteen Islamic countries. Social Behavior and Personality: an international journal. 2005;33(7):675-84.

26. Alansari BM. Gender differences in depression among undergraduates from seventeen Islamic countries. Social Behavior and Personality: an international journal. 2006;34(6):729-38. 
27. Lustman PJ, Clouse RE, Griffith LS, Carney RM, Freedland KE. Screening for depression in diabetes using the Beck Depression Inventory. Psychosom Med. 1997;59(1):24-31.

28. Thabet AA, Tawahina AA, Tischler V, Vostanis P. PTSD, depression, and anxiety among Palestinian women victims of domestic violence in the Gaza Strip. Brit J Education, Society \& Behavioural Science. 2015;11(2):1-13.

29. Madianos MG, Sarhan AL, Koukia E. Major depression across West Bank: a cross-sectional general population study. Int J Soc Psychiatry. 2012;58(3): 315-22.

30. Stasiak CE, Bazan KS, Kuss RS, Schuinski AF, Baroni G. Prevalence of anxiety and depression and its comorbidities in patients with chronic kidney disease on hemodialysis and peritoneal dialysis. J Bras Nefrol. 2014;36(3): 325-31.

31. Teles F, Azevedo VF, Miranda CT, Miranda MP, Teixeira Mdo C, Elias RM. Depression in hemodialysis patients: the role of dialysis shift. Clinics (Sao Paulo). 2014;69(3):198-202.

32. Ossareh S, Tabrizian S, Zebarjadi M, Joodat RS. Prevalence of depression in maintenance hemodialysis patients and its correlation with adherence to medications. Iran J Kidney Dis. 2014;8(6):467-74.

33. Al Zaben F, Khalifa DA, Sehlo MG, Al Shohaib S, Shaheen F, Alhozali H, Hariri AO, Ahmad RG, Kabli MR, Koenig HG. Depression in patients with chronic kidney disease on dialysis in Saudi Arabia. Int Urol Nephrol. 2014;46(12): 2393-402.

34. Molarius A, Berglund K, Eriksson C, Eriksson HG, Lindén-Boström M, Nordström E, Persson C, Sahlqvist L, Starrin B, Ydreborg B. Mental health symptoms in relation to socio-economic conditions and lifestyle factors--a population-based study in Sweden. BMC Public Health. 2009;9:302.

35. Tsutsui H, Nomura K, Ishiguro A, Tsuruta Y, Kato S, Yasuda Y, Uchida S, Oshida Y. Factors associated with employment in patients undergoing hemodialysis: a mixed methods study. Renal Replacement Therapy. 2017; 3(1):23.

36. Craft LL, Perna FM. The benefits of exercise for the clinically depressed. Prim Care Companion J Clin Psychiatry. 2004;6(3):104-11.

37. Blumenthal JA, Smith PJ, Hoffman BM. Is exercise a viable treatment for depression? ACSMs Health Fit J. 2012;16(4):14-21.

38. DiMatteo MR, Lepper HS, Croghan TW. Depression is a risk factor for noncompliance with medical treatment: meta-analysis of the effects of anxiety and depression on patient adherence. Arch Intern Med. 2000; 160(14):2101-7.

39. MacLeod A, Grant A, Donaldson C, Khan I, Campbell M, Daly C, Lawrence P, Wallace S, Vale L, Cody J, et al. Effectiveness and efficiency of methods of dialysis therapy for end-stage renal disease: systematic reviews. Health Technol Assess. 1998;2(5):1-166.

\section{Publisher's Note}

Springer Nature remains neutral with regard to jurisdictional claims in published maps and institutional affiliations.

Ready to submit your research? Choose BMC and benefit from:

- fast, convenient online submission

- thorough peer review by experienced researchers in your field

- rapid publication on acceptance

- support for research data, including large and complex data types

- gold Open Access which fosters wider collaboration and increased citations

- maximum visibility for your research: over $100 \mathrm{M}$ website views per year

At $\mathrm{BMC}$, research is always in progress.

Learn more biomedcentral.com/submissions 